\title{
HÁ ALGO NOVO A SE DIZER SOBRE AS RELAÇÕES RACIAIS NO BRASIL CONTEMPORÂNEO?
}

\author{
VALTER Roberto SILVÉRIO* \\ CRISTINA TEOdoRo TRINIDAD ${ }^{* *}$
}

\begin{abstract}
A raça, no nosso sentido mais amplo, foi transformada em uma parte importante das condições de processos políticos, econômicos e sociais de grande parte do mundo. A Organização das Nações Unidas tornou-se um órgão mundial de opinião que faz com que cada problema racial doméstico (nacional) transforme-se em um problema internacional e diplomático.
\end{abstract}

(Hughes, 1963, p. 884-885)

\begin{abstract}
RESUMO: A aprovação da Lei n. 10.639-2003 e suas diretrizes, que alteraram a Lei de Diretrizes e Base da Educação Brasileira (LDB), pressupõem um conjunto de mudanças substantivas que passam a alterar a política pública educacional no país. A obrigatoriedade da educação das relações étnico-raciais e do ensino de história e cultura afro-brasileira e africana em toda a educação básica é resultado tanto do reconhecimento da discriminação racial e do racismo como constitutivos de nossa formação social, quanto permite desvendar as contribuições das culturas africanas na constituição de nossa brasilidade para além do trabalho escravo. A identidade negra, produto político do apagamento da multiplicidade cultural de povos que aportaram no país, passa a dar lugar ao prefixo afro como possibilidade de novas identificações e recriações dos brasileiros descendentes de africanos, as quais podem ser analisadas a partir do conceito de diáspora.
\end{abstract}

Palavras-chave: Educação das relações étnico-raciais. Afro-brasileiro. Desigualdades. Diáspora africana.

* Doutor em Ciências Sociais e professor associado do Programa de Pós-Graduação, Departamento de Sociologia da Universidade Federal de São Carlos (Ufscar). E-mail: silverio@ufscar.br

** Doutora em Psicologia da Educação e oficial de Projetos do Setor de Educação da Unesco no Brasil. E-mail: cristina.trinidad@unesco.org.br 


\section{IS THERE ANYTHING NEW TO SAY ABOUT RACIAL RELATIONSHIPS}

\section{IN CONTEMPORARY BRAZIL?}

ABSTRACT: The Law n. 10.639-2003 and it's directives approval, which had changed the Law of Directives and Basis for Brazilian Education, assumes a set of substantial changes that has begun to alter the educational public policies in the country. The obligatoriness of ethnic-racial education, as well as afro-Brazilian and African historical and cultural studies in basic education, is a result of the acknowledgement of both racial discrimination and racism as constitutive elements of our social development, as it allows unveiling the African contributions to our Brazilian identity far beyond slavery. The black identity, as a product of cultural multiplicity's political erasure of the people who landed in the country, give place to the prefix afro as a new identification and recreation possibility for the Brazilians who descend from the Africans. This identity can be analyzed trough the diaspora concept.

Key words: Ethnic-racial education. Afro-Brazilian. Inequalities. African diaspora.

\section{Y A-T-IL QUELQUE CHOSE DE NOUVEAU A DIRE SUR LES RELATIONS RACIALES DANS LE BRÉSIL CONTEMPORAIN?}

RÉSUMÉ: L'approbation de la Loi n. 10.639-2003 et de ses directives, qui ont modifié la Loi de Directives et Base de l'Educação Brésilienne (LDB), présupposent un ensemble de changements substantiels qui modifient la politique publique éducative dans le pays. L'obligation de l'éducation des relations ethno-raciales et celle de l'enseignement de l'histoire et de la culture afro-brésilienne et africaine dans toute l'éducation primaire est le résultat de la reconnaîssance de la discrimination raciale et du racisme en tant que constitutifs de notre formation sociale, tout comme elle permet de dévoiler les contributions des cultures africaines dans la constitution de notre brésilianité au-delà du travail esclave. L'identité noire, produit politique de l'effacement de la multiplicité culturelle des peuples qui l'apportèrent dans le pays, donne lieu au préfixe afro comme possibilité de nouvelles identifications et recréations des brésiliens descendants d' Africains, lesquelles peuvent être analysées à partir du concept de diaspora.

Mots-clés: Éducation des relations ethno-raciales. Afro-brésilien. Inégalités. Diaspora africaine. cada pela Lei n. 10.639-2003 e as Diretrizes Curriculares Nacionais para a Educação das Relações Étnico-raciais e para o Ensino de História e Cultura Afro-brasileira e Africana - de acordo com a homologação, em 18 de maio de 2004, do Parecer n. 03/2004, de 10 de março, do Conselho Pleno do Conselho Nacional de Educação, aprovando o projeto de resolução dessas diretrizes que as acompanham podem ser consideradas um novo marco na história da educação do país. Em seu conjunto, elas representam transformações substantivas que refletem mudanças sociais profundas na forma como nossa sociedade se autoimagina e se representa enquanto uma comunidade. 
O presente artigo entende que a obrigatoriedade da educação das relações étnico-raciais e do ensino de história e cultura afro-brasileira e africana em toda a educação básica é resultado do reconhecimento da discriminação racial e do racismo como constitutivos de nossa formação social. As Diretrizes, também, abrem novas possibilidades de interpretação das contribuições das culturas africanas na constituição de nossa brasilidade para além do trabalho escravo e da invisibilidade proporcionada pelo mito da democracia racial. Não se trata de negar a hibridação cultural, mas de reconhecê-la a partir de suas diversas matrizes presentes nas narrativas de construção da nação. E, por último, o artigo compreende que a educação, como política pública que atravessa a experiência de todos os brasileiros, ou daqueles que "optaram" por viver no país, ganha relevância como lugar onde aquelas mudanças, e as reações às mesmas, se concretizam de forma tensa a partir da ação do movimento negro brasileiro.

\section{Uma visão do contexto histórico}

Nos últimos vinte anos, o Núcleo de Estudos Afro-Brasileiros da Universidade Federal de São Carlos (Neab/Ufscar) e vários outros núcleos e grupos similares espalhados pelo país vêm realizando um conjunto de ações acerca das relações étnico-raciais e a educação. A reflexão desenvolvida por estudantes e professores durante esse período tem procurado relacionar tanto a reflexão teórica quanto a intervenção social. Assim, as dissertações, teses e artigos produzidos pelos núcleos e grupos registraram com maior ou menor intensidade os eventos e acontecimentos do período posterior à promulgação da Constituição de 1988.

De acordo com Rodrigues (2011, p. 11), duas dimensões se sobressaem no debate educacional contemporâneo, a saber: a primeira, a interlocução entre educação e "raça", a qual se relaciona com a busca de uma educação mais equitativa, que tem como pressuposto a extinção das desigualdades educacionais proporcionadas pela articulação de má distribuição da riqueza econômica e não reconhecimento adequado de grupos sociais partícipes de nossa formação social; a segunda está relacionada à mudança na forma de atuação do Estado, pressionado pela ação política do movimento negro brasileiro que, desde seu ressurgimento em 1978, denunciava a discriminação racial e o racismo e, ao mesmo tempo, clamava por educação pública de qualidade.

No primeiro caso, a questão dos conteúdos curriculares, a formação de professores e as condições estruturais da educação básica pública no Brasil compõem, sem prejuízo de outras dimensões, o núcleo dos debates nas últimas décadas. No segundo caso, a centralidade que a educação escolar adquire para o desenvolvimento nacional, desde a última década do século anterior, vem transformando essa política pública no principal instrumento de inclusão social tanto na perspectiva de vários 
movimentos sociais, quanto no discurso das autoridades estatais em seus diferentes níveis.

Na Assembleia Nacional Constituinte, em 1987, mesmo em uma correlação desfavorável de forças, pudemos observar que os vários encontros organizados pelo movimento negro tinham como foco a participação nos debates. A temática étnico-racial foi incorporada à Comissão "Da Ordem Social”, a partir das discussões ocorridas na "Subcomissão dos Negros, Populações Indígenas, Pessoas Deficientes e Minorias". Segundo Rodrigues (2005), o movimento negro conseguiu debater e elaborar importantes propostas das quais é possível destacar as seguintes: a) reconhecimento e demarcação das terras das comunidades negras remanescentes de quilombos; b) criminalização da prática de racismo e preconceito racial; c) comprometimento da política educacional no combate ao racismo e todas as formas de discriminação, respeito à diversidade e obrigatoriedade do ensino de história das populações negras do Brasil. Somada a essas propostas, foi discutida a importância de ações afirmativas voltadas à população negra. O texto final da Constituição incorporou a proposta de que o currículo deveria abarcar, com igualdade, as contribuições das diferentes etnias e grupos que participaram do processo de formação do povo brasileiro.

De acordo com Silvério (2005), a questão de fundo no debate, desde as duas últimas décadas do século XX na sociedade brasileira, é sobre o lugar da diversidade e em que medida o seu reconhecimento tem contribuído para recriar a ordem social, cultural e política. Para o autor, a Constituição Federal de 1988 reflete uma transição sociopolítica de uma sociedade que se representava como homogênea (do ponto de vista étnico-racial), harmônica (do ponto de vista do ideal de nação) e cordial (do ponto de vista das relações entre os indivíduos e grupos), para uma sociedade que se pensa diversa e profundamente heterogênea (do ponto de vista étnico-racial), dissonante (do ponto de vista do ideal de nação) e conflituosa (do ponto de vista das relações entre os indivíduos e grupos) (Silvério, 2005).

O período entre a promulgação da Constituição de 1988 e a aprovação da Lei n. 10.639/03 é de extrema importância para a compreensão das mudanças sociais em curso, tanto em um contexto nacional quanto transnacional. Alguns dos marcos que nos servem como referência são os seguintes: a Marcha Zumbi dos Palmares (1995), a aprovação da Lei de Diretrizes e Bases da Educação Nacional n. 9.394/1996 (LDB), os Seminários Regionais Preparatórios para Conferência Mundial Contra o Racismo, Discriminação Racial, Xenofobia e Intolerância Correlata, ${ }^{1}$ a III Conferência Mundial das Nações Unidas Contra o Racismo, Discriminação Racial, Xenofobia e Intolerância Correlata, realizada pela Organização das Nações Unidas (ONU) em Durban, na África do Sul (2001) e, por fim, a aprovação da alteração da LDB pela Lei n. 10.639/2003, bem como sua regulamentação. Em relação à sua efetiva implementação, durante todo o ano de 2008 ocorreram seis encontros 
regionais (dois no Nordeste e um em cada região do país) e um encontro nacional, os quais serviram de base para a construção de um plano. ${ }^{2}$

A Marcha Zumbi dos Palmares - contra o racismo, pela cidadania e a vida foi organizada pelo movimento negro no ano de 1995, tendo como tema central a homenagem aos 300 anos da morte de Zumbi dos Palmares. Os desdobramentos da Marcha ganharam relevância no cenário político nacional com a instalação, em 1996, durante o Governo Fernando Henrique Cardoso, do Grupo de Trabalho Interministerial para a Valorização da População Negra (GTI). Este teve um papel fundamental no reconhecimento, por parte do Estado brasileiro, do racismo em nossa sociedade.

A III Conferência Mundial das Nações Unidas Contra o Racismo, Discriminação Racial, Xenofobia e Intolerância Correlata, realizada pela ONU em Durban, na África do Sul (2001), é considerada como fundamental no estabelecimento de uma série de ações políticas como, por exemplo, as recomendações sobre a adoção das cotas para estudantes negros nas universidades públicas e a criação do Conselho Nacional de Combate a Discriminação. A sua revisão, em 2009, em Genebra, reafirmou a Declaração e Programa de Ação de Durban (DDPA), conforme foi adotado na Conferência Mundial em 2001, e expressou preocupações com o "fato de que os desafios e obstáculos identificados no DDPA permaneciam pendentes de superação para erradicar, prevenir e combater efetivamente o racismo, a discriminação, a xenofobia e a intolerância correlata" (Revisão de Durban, Seção 1).

As deliberações propositivas da Conferência repercutiram também na criação de duas secretarias voltadas à questão étnico-racial, a educação e a diversidade, durante o governo do presidente Luís Inácio Lula da Silva. São elas: a Secretaria Especial de Políticas de Promoção da Igualdade Racial (Seppir), ${ }^{3}$ com status de Ministério, e a Secretaria de Educação Continuada, Alfabetização e Diversidade (Secad), ${ }^{4}$ vinculada ao Ministério da Educação.

Foi de grande importância o reconhecimento oficial, pelo Estado, da existência do racismo e da discriminação racial no país, como já exposto. A partir da década de 1990 notam-se esforços do poder público, voltados ao combate do racismo e do preconceito no ambiente escolar, principalmente, por meio da adoção de medidas direcionadas ao atendimento das reivindicações pautadas nas questões étnico-raciais. São alguns dos marcos: o Programa de Superação do Racismo e da Desigualdade Racial que, segundo Rodrigues (2005, p. 67), apresentou "a necessidade de reorganização da escola a partir da diversidade, o que compreende a revisão da estrutura educacional, dos livros didáticos, a implementação de programas de formação permanente de professores que os habilitem a tratar adequadamente a diversidade racial"; os Parâmetros Curriculares Nacionais (PCNs), por meio do tema transversal "Pluralidade e Cultura", 5 o Programa Nacional do Livro Didático ${ }^{6}$ (PNLD) e o manual "Superando o Racismo na Escola". 
Segundo Gonçalves e Silva (2003, p. 120),

(...) tendo em vista que a cultura e sua transmissão contam, nas sociedades contemporâneas, com poderoso suporte dos sistemas educacionais (sistemas estes que consomem grande parte da vida dos indivíduos) e como a educação, qualquer que ela seja, está integralmente centrada na cultura, pode-se entender porque os multiculturalistas fizeram da instituição escolar seu campo privilegiado de atuação.

A inserção e a valorização de culturas diferentes das ocidentais, muitas vezes de culturas originárias de populações do continente africano, no Brasil, participam ativamente na formação de diversos processos e práticas culturais como integrantes do debate contemporâneo, haja vista como a valorização de processos históricos advindos de culturas negras, bem como de sujeitos que assim se identificam, corresponderia à formatação de um processo similar à vivência da história na história, no qual os valores da população negra seriam repensados, reconhecidos e valorados positivamente (Rodrigues, 2005). Assim, é preciso reconhecer que a educação permaneceu como a política pública prioritária para o movimento negro, a partir da crença de que o fim das desigualdades educacionais e sociais geradas pelos históricos de práticas de racismo e discriminação direcionados aos não brancos só se dará com mais e melhor educação formal.

Nesse sentido, a aprovação da Lei n. 10.639/03 e a implementação da Resolução n. 3/2004 e do Parecer do Conselho Nacional de Educação (Conselho Pleno 001/2004), que estabelece a obrigatoriedade da temática "História e Cultura Afro-Brasileira" no currículo oficial da rede de ensino da educação básica, iniciam a perspectiva de visibilidade e do reconhecimento desses sujeitos e suas experiências, isto é, “(...) indica[m] a possibilidade de romper com o paradigma eurocêntrico e estimula[m] alterações nas formulações de políticas educacionais, na medida em que pode[m] implicar a ampla modificação curricular inclusive nos cursos de formação de professores e de todos os profissionais da educação" (Rodrigues, 2005, p. 63).

Entretanto, no período que sucedeu ao sancionamento da lei que alterou a LDB, observamos um recrudescimento do debate sobre uma suposta bipolarização racial, na visão de alguns acadêmicos que essencializam a mestiçagem do povo brasileiro, provocada pelo Estado nacional e organizações não governamentais (ONGs). O que pudemos aprender com o debate?

\section{Uma "gênese" do impacto da ideia de raça}

O maior aprendizado foi que o termo raça continua presente em nosso imaginário social com uma variação tão vasta de entendimentos quanto a sua variabilidade de usos imprecisos. Dessa forma, nos cabe precisar em que sentido o termo 
foi apropriado no âmbito desse texto. No caso brasileiro, por tratar-se de uma ideia extremamente polêmica, na atualidade, "raça" encontra-se no centro do dissenso. Como ponto de partida, tomemos a definição estabelecida pelo Dicionário da Real Academia Espanhola. Da origem latina radia, de radius, aparece com sete significados no referido dicionário, entre os quais nos interessa o segundo: "Cada uno de los grupos en que se subdividen algunas especies biológicas y cuyos caracteres diferenciales se perpetúan por herencia". ${ }^{7}$ Esta definição, que durante o século XIX impregnou o pensamento social, por meio da antropologia física, passou a ser entendida como parte de um sistema de classificação por meio do qual se pretendeu ordenar e interpretar as diferenças visíveis - fenotípicas e socioculturais - da espécie humana.

Porém, é voz corrente que o termo raça não foi gestado exclusivamente no âmbito científico, como demonstra o seu primeiro significado no referido dicionário: "casta o calidad del origen o linaje". ${ }^{8}$ Relacionando o termo ao livro Gênesis, ele remete aos três filhos de Noé - Sem, ${ }^{9}$ Cam e Jafet - a descendência das três raças: branca, negra e amarela. Nessa concepção, o conceito de raça remete a uma dada comunidade, com um imaginário particular, a qual dá forma a uma série de discursos de origem que permitem pensar e assumir suas raízes comuns e suas diferenças em relação a outras comunidades.

Assim, a ideia de raça, para além de seus significados acadêmico-científicos, tornou-se de uso generalizado com inúmeras conotações que, também, permitem pensá-la como referida a "calidad de algunas cosas, en relación a ciertas características que lãs definen".$^{10}$ Pode-se deduzir que, do ponto de vista ideológico, certos grupos se pensam, e pensam a outros, a partir da descrição de diferenças observáveis, definindo qualidades e atribuindo valores em detrimento de outros valores e qualidades por considerá-los indesejáveis, contribuindo para o processo de sua estigmatização.

Com Stuart Hall, aprendemos que a ideologia se refere aos referenciais "mentais - linguagens, conceitos, categorias, conjunto de imagens do pensamento e sistemas de representação - que as diferentes classes e grupos sociais empregam para dar sentido, definir, decifrar e tornar inteligível a forma como a sociedade funciona" (Hall, 2004, p. 267). Para o autor, o problema da ideologia é concernente às formas pelas quais ideias diferentes tomam conta das mentes das massas e, por esse intermédio, se tornam uma "força material". Assim, a teoria da ideologia nos ajuda a compreender "os conceitos e linguagens do pensamento prático que estabilizam uma forma particular de poder e dominação; ou que reconciliam e acomodam as massas em seu lugar subordinado na formação social" (idem, ibid.).

Em relação às ideologias raciais, para além das teorias racialistas, elas podem fornecer o mapa de posições e relações sociais existentes em um contexto histórico 
preciso (incluindo as relações de dominação), as quais serviram de justificativa para as mais diversas formas de subordinação. No caso brasileiro, é visível a influência exercida pela ideia de que somos uma "democracia racial" que nos iguala simbolicamente em termos de uma mistura genética e cultural; e, também, que nos hierarquiza em termos cromáticos nas relações sociais cotidianas, posicionando os indivíduos não brancos em uma escala de qualidades e valores observáveis nas posições que eles ocupam, por exemplo, no mercado de trabalho.

Ao se considerar as Ciências Sociais como uma leitura ocidental, e o seu desenvolvimento no marco do encontro entre a cultura ocidental e as não ocidentais - africanas, asiáticas e americanas -, em toda a sua diversidade podemos dizer que a gênese do conceito de raça - como conceito acadêmico - está determinada por um questionamento ocidental que pode ser resumido da seguinte forma: Por que eles não são como nós?

São os processos de luta de libertação ocorridos na Ásia e na África que demonstram como a diferença apropriada de forma "qualitativa" e "valorativa" significou uma forma de dominação ocidental baseada na ideia de inferioridade, justificada pela ciência desenvolvida nos países europeus (França, Inglaterra e Alemanha) e, posteriormente, nos Estados Unidos da América. A gestação e cristalização de tradições teóricas ancoradas em paradigmas endógenos, os quais consubstanciaram a centralidade da Europa como ponto preferencial e de referência no debate acadêmico-científico, foi coetânea da percepção dos "subalternos" - americanos, asiáticos e africanos - da maneira como sua subalternidade havia sido construída e das insuficiências dos esquemas acadêmicos tradicionais.

Para Slenes (2010, p. 19), por exemplo, o descentramento tem levado a uma mudança na percepção dos pesquisadores da relação "centro-periferia":

A relação entre "centro" e "periferia" no mundo moderno foi radicalmente redefinida a partir de uma perspectiva dialética, enfatizando a profunda interação e interprenetração entre esses dois "extremos". Paralelamente, no imaginário dos pesquisadores, os "subalternos" (os "de baixo" na pirâmide social) ganharam voz, pensamento estratégico e participação ativa no processo histórico.

As (re)apropriações do termo raça, no cenário político-acadêmico brasileiro, nada tem de essencialização do antigo conceito de matriz biológica; ao contrário, seu uso tem demonstrado um grande potencial no desvendamento da racialização $0^{11}$ pretérita da sociedade brasileira. Como conceito analítico, a ideia de raça foi utilizada particularmente na biologia e na antropologia física, como uma categoria de diferença suscetível de ser apropriada para analisar e interpretar a diversidade existente entre grupos humanos, tomando por base a interpretação de certos caracteres hereditários. Assim concebida, a noção de raça passou a interpretar - e confundir 
- as características biológicas e culturais ao constituir grupos sociais diferenciados, com base em critérios assumidos como naturais e, portanto, invariáveis. A Segunda Guerra pode ser considerada o marco de uma mudança fundamental em relação ao uso do conceito tanto no que diz respeito aos desenvolvimentos científicos, quanto quando consideramos os genocídios ocorridos ao longo do século XX. O descrédito em relação ao seu uso se deu pela observação por parte dos cientistas que o viam como o núcleo de um discurso discriminador, e com base em argumentos biogenéticos ele deixou de ser utilizado como categoria de classificação.

Numa outra perspectiva de análise, a partir da contribuição de Hall (2004, p. 294-334), em especial a sua leitura da obra de Gramsci, é possível retrabalhar algumas teorias "e paradigmas existentes na análise do racismo e de outros fenômenos sociais relacionados". Entre os aspectos elegidos pelo autor cabe, no âmbito do presente artigo, ressaltar os seguintes: a) a ênfase sobre a especificidade histórica na análise das formas de racismo; $b$ ) o peso das características nacionais e as irregularidades regionais por não haver "lei de desenvolvimento homogênea" que afete da mesma forma cada elemento de uma dada formação social; c) a abordagem não redutiva das questões que concernem aos interrelacionamentos de classe e raça; d) o caráter não homogêneo do "sujeito de classe"; e) a não correspondência no modelo gramsciano entre as dimensões econômica, política e ideológica; f) a distinção de Gramsci entre dominação e direção pode fornecer elementos para uma análise não unidimensional da função do Estado em relação ao seu papel "educativo" e seu "caráter ideológico", isto é, sua posição na "construção de estratégias hegemônicas poderia transformar o estudo tanto do Estado em relação às práticas racistas quanto dos fenômenos relacionados ao 'Estado pós-colonial'".

Assim para Hall, a obra de Gramsci dá relevância prioritária ao terreno das práticas, representações, linguagens e costumes concretos, isto é, ao fator cultural de qualquer sociedade historicamente específica, "incluindo as formas contraditórias de 'senso comum' que se enraízam e ajudam a moldar a vida popular". O interesse de Hall é pelas várias distinções que Gramsci associa ao termo "nacional popular" como lugar privilegiado para a construção da hegemonia e referência-chave dos objetos de luta e da prática política e ideológica (Hall, 2004, p. 332).

É com o pano de fundo descrito anteriormente que Brah (1996), seguindo Hall, argumenta que a partir da rejeição da fundamentação genética de raça, o conceito passou a ser entendido como uma construção social, com destaque para seu uso em relação a contextos discursivos concretos que, desde o terreno do imaginário e do simbólico, fazem referência a processos amplos de construção de identidades sociais. Para a autora, longe de cair nas representações essencialistas, a ideia passa a ser considerada em relação a práticas discursivas e materiais concretas, portanto, como uma categoria historicamente contingente (Brah, 1996). 


\section{Anotações sobre a reconfiguração do nacional popular}

No período de (des)escravização do Império e durante o estabelecimento da primeira República, o desejo de se constituir um povo com as características fenotípicas dos principais Estados nacionais europeus por parte de nossas elites estava em frontal contraste com o estoque populacional existente nas diversas regiões do país. Para Miskolci (2012), por exemplo, no final do século XIX,

(...) entre as aspirações de progresso e os temores de degeneração racial, a elite brasileira nutria o desejo de criar uma "civilização nos trópicos". Esse ideal político, intelectual e econômico contribuiu para acontecimentos como a Abolição da Escravatura, a Proclamação da República e, sobretudo, a consolidação de uma espécie de projeto nacional tão modernizante quanto autoritário. Nascia, assim, o sonho do Brasil como construção futura, desejo hostil ao seu passado e, também, hostil à sua população, recusada e temida como parte do que se queria superar.

Ao prosseguir em seu argumento, com base na análise do romance Bom crioulo, de Adolfo Caminha, publicado em 1895, Miskolci (op. cit.) observa que

(...) as elites do período, guiadas por um desejo que orientou o projeto político de constituição da nação brasileira, consideravam que as classes populares eram desqualificadas para aquele projeto. Entre os elementos que as desqualificavam estava a sua negritude ou branquitude incompleta, fruto de um processo de racialização que é também de sexualização. Amaro, personagem do romance, não é desqualificado apenas por ser negro, antes porque a negritude o aloca na esfera da sexualidade sem controle, uma esfera carente de moralidade.

A reflexão em torno do ideal de homogeneidade permite observar que havia um acordo tácito entre nossos intelectuais, políticos e elite econômica, tanto em relação à inadequação do povo para a formação da nação, devido ao seu caráter heterogêneo, quanto à forma que a nação era imaginada como sinônimo de homogeneidade racial e de harmonia política ou, melhor dizendo, de branquitude e civilização. A mudança nesta perspectiva, com a "aceitação" da diversidade e pluralidade da população existente no país, tem origem na ideia de que algo de novo estava em desenvolvimento no novo mundo. A ideia de que o Brasil era um "laboratório de civilização" foi expressa em texto de Rüdiger Bilden (1929) e, em 1930, ela se expandiu para o Novo Mundo por meio de Melville Herskovits; Gilberto Freyre, em 1935, considerou o país um "laboratório" para os estudos de africanismos ou de relações raciais:

Inspirando-se fortemente nas ideias de Freyre expressas nas conferências da Europa (em Lisboa e Londres) sobre "democracia social" brasileira e a matriz cultural lusitana, transformando a mestiçagem em um mecanismo de integração e mobilidade social dos povos colonizados, Dr. Ramos passará a ser o principal intelectual brasileiro a divulgar o Brasil como "democracia racial" e um "laboratório de civilização". (Guimarães, 2002, p. 52) 
No entanto, as experiências em curso em nosso "laboratório civilizacional" deveriam resultar em uma síntese mestiça, isto é, na fusão das três raças das quais o povo brasileiro teria a sua origem. Para além das discussões que conferem ao "mito da democracia racial" sua eficácia simbólica e prática na construção de nossas representações como uma comunidade nacional imaginada, a mestiçagem ${ }^{12}$ e a miscigenação, realmente existentes, têm sido deslocadas de seu sentido anterior, no qual pouca ou nenhuma importância era conferida às origens ancestrais de muitos, para um reconhecimento de sua centralidade no processo de estigmatização ou mobilidade de um grupo. Dessa forma, o imaginário social que conferia à mestiçagem o estatuto prioritário de nomeação de boa parte dos brasileiros, encobrindo suas origens, tem dado lugar, por exemplo, aos prefixos afro, euro, entre outros.

Guimarães (2002, p. 166), por exemplo, avança na compreensão da democracia racial não apenas como um mito ou construção cultural, mas também como um tácito "compromisso" ou "pacto" político de "integração dos negros à nação brasileira, em termos simbólicos, por meio da adoção de uma cultura nacional mestiça e sincrética, e em termos materiais, pelo menos parcialmente, através da regulamentação do trabalho e da seguridade social". Segundo o autor, o movimento negro organizado, nesse período, focou suas ações no combate ao preconceito racial por meio de políticas universalistas de integração do negro à sociedade moderna. O golpe militar de 1964, porém, destruiu o pacto e estremeceu os elos do protesto negro com o sistema político e, a partir daí, as acusações de que a democracia racial é um mito, que forja as relações racistas, ganhou força no movimento negro por todo o país (Santos, 2010).

De acordo com Santos (op. cit.), a representação da mestiçagem encarnou nos brasileiros, por meio do ideal da democracia racial, o não reconhecimento da existência e, consequentemente, da relevância das raças na formação e na dinâmica social brasileira, estas entendidas como cordiais e assimilacionistas. Este não reconhecimento das raças resultou na dedução da inexistência do racismo, ou melhor, confiaram que o antirracialismo promoveria o antirracismo no país. Entretanto, sorrateiramente, as práticas racistas permaneceram (e permanecem), marginalizando, simbólica e materialmente, os negros.

Ao se observar o preâmbulo da Constituição Federal de 1988, tem-se a impressão de que a concepção de "democracia racial" permanece presente. No entanto, ela contém uma série de desencontros e sinonímias decorrentes da pouca precisão na forma de termos como, por exemplo, "preconceito", "prática de racismo", "diferença de tratamento" e "discriminação" (Santos, 2010).

Nós, representantes do povo brasileiro, reunidos em Assembléia Nacional Constituinte para instituir um Estado democrático, destinado a assegurar o exercício dos direitos sociais e individuais, a liberdade, a segurança, o bem-estar, o desenvolvimento, a igualdade e a justiça como valores supremos de uma sociedade fraterna, pluralista e sem 
preconceitos, fundada na harmonia social e comprometida, na ordem interna e internacional, com a solução pacífica das controvérsias, promulgamos, sob a proteção de Deus, a seguinte Constituição da República Federativa do Brasil. (Brasil, 1998, Preâmbulo)

A tensão entre a visão de que somos uma comunidade imaginada homogênea, fraterna e harmônica está em contradição com o próprio texto constitucional, e pode ser explicada pela erosão paulatina do discurso da "democracia racial" e pela emergência de um "novo" discurso, em tese mais representativo, das aspirações populares em se ver representada em suas diferenças de origem étnico-racial, isto é, uma comunidade que se imagina diversa culturalmente.

Nesse sentido, ao se revisitar o argumento de Anderson (2008) de que a identidade nacional é uma "comunidade imaginada" em suas consequências, nem sempre analisadas em nosso país, é possível uma nova compreensão das mudanças sociais em curso, em especial no que diz respeito à diversidade étnico-racial brasileira, como segue: a primeira é que as culturas nacionais são compostas não somente de instituições culturais, mas de símbolos e representações. Uma cultura nacional é um discurso - uma maneira de construir significados que influenciam e organizam tanto nossas ações, quanto nossas concepções sobre nós mesmos; a segunda é que tais culturas nacionais constroem identidades ao produzirem significados sobre a "nação" com os quais podemos nos identificar. Estes significados estão contidos nas histórias que são contadas sobre ela, nas memórias que conectam seu presente com seu passado, e nas imagens que são construídas a propósito das nações.

De acordo com Bhabha (2010, p. 11), “as nações, como narrativas, perdem suas origens nos mitos do tempo e somente percebem inteiramente seus horizontes nos olhos da mente". Daí a importância de nos perguntarmos: Como a narrativa da cultura nacional é contada?

Segundo Hall (op. cit.), cinco aspectos importantes se destacam, dentre muitos, para uma resposta compreensível à questão:

1) A narrativa da nação, contada e recontada nas histórias e literaturas nacionais, na mídia e na cultura popular, oferece um conjunto de histórias, imagens, paisagens, cenários, eventos históricos, símbolos e rituais nacionais que sustentam, ou representam, as experiências, as tristezas compartilhadas, os triunfos e desastres que dão sentido à nação;

2) Há ênfase nas origens, na continuidade, na tradição e na atemporalidade. A identidade nacional é representada como primordial. $\mathrm{O}$ essencial do caráter nacional permanece imutável através de todas as vicissitudes da história;

3) “(...) a tradição inventada [significa] um conjunto de práticas, (...) de uma 
natureza simbólica ou ritual que procuram inculcar certos valores e normas de comportamento através da repetição que automaticamente implica a continuidade de um passado histórico adequado" (Hobsbawn \& Ranger, 1983, p. 1);

4) O mito fundante é uma história que localiza a origem da nação, as pessoas e suas características nacionais como tão antigas que elas estão perdidas na névoa do tempo, não "real", mas mítico;

5) A identidade nacional é também, muitas vezes, baseada simbolicamente na ideia de um povo ou "folk" puro, original.

Desse modo, uma cultura nacional funciona como uma fonte de significados culturais, como um foco de identificação e como um sistema de representação. Em seu famoso ensaio sobre o assunto, Renan (2010) nos diz que três coisas constituem o princípio da unidade da nação: a posse comum de um legado de memória (memórias do passado); o desejo de viver conjuntamente (o desejo de vida em comum); a vontade de perpetuar a herança que se recebeu em uma forma indivisível (a perpetuação da herança).

Thimothy Brenan nos lembra de que a palavra nação refere-se "tanto ao Estado nacional moderno quanto a algo mais antigo e nebuloso - a natio -, uma comunidade local, domicílio, família, condição de pertença" (Brennan, 2010, p. 66). As identidades nacionais representavam precisamente o resultado da junção destas duas metades da equação nacional - oferecendo tanto a filiação política ao Estado nacional, quanto a identificação com a cultura nacional: "tornar cultura e política congruentes" e favorecer "as culturas razoavelmente homogêneas, cada qual com seu próprio teto político" (Gellner, 1983, p. 43).

A nossa hipótese é de que o deslocamento na forma como a sociedade brasileira se autorrepresentava é decorrente do processo de luta política pela (des)racialização da experiência coletiva da população negra. Com base nas conquistas do movimento negro é possível destacar alguns aspectos que permitem sustentar essa linha de raciocínio, a saber: 1) o tratamento político-jurídico da temática da diversidade e da igualdade racial na Constituição de 1988; 2) a alteração da Lei de Diretrizes e Bases da educação brasileira, e as diretrizes que a acompanham, orienta para uma mudança significativa nos conteúdos curriculares nacionais, ao prescrever a obrigatoriedade de uma educação que possibilite a construção de relações étnico-raciais saudáveis e que inclua a história e a cultura afro-brasileira e africana e, também, indígena. E, finalmente, a interação entre as mudanças internas e o papel que o Brasil passou a representar transnacionalmente nos últimos anos, não exclusivamente, mas em especial para os países da comunidade de língua portuguesa do continente africano. Um dos resultados desse processo é o programa que vem sendo desenvolvido pela Organização 
das Nações Unidas para a Educação, a Ciência e a Cultura (Unesco), baseado no seu escritório em Brasília, em parceria com o Ministério da Educação, intitulado "Brasil-África: histórias cruzadas".

De acordo com Silva Jr. (2012), a Constituição de 1988 representa, também, um marco no tratamento político-jurídico da temática da diversidade e da igualdade racial, como um dos reflexos da atuação política do movimento negro. Para o autor, alguns aspectos merecem destaque:

1) A reconsideração do papel da África na formação da nacionalidade brasileira;

2) O reconhecimento do caráter pluriétnico da sociedade brasileira como fundamento constitucional do currículo escolar;

3) O direito constitucional à identidade étnica como fundamento do currículo escolar;

4) A cultura negra como base do processo civilizatório nacional e como um eixo estruturante do currículo escolar.

Uma leitura possível das diretrizes, conhecidas também como Parecer Petronilha, frente ao plano nacional de sua implementação, verifica que estas, em suas questões introdutórias, procuram oferecer uma resposta na área de educação à demanda da população afrodescendente por políticas de ação afirmativa, entendida tanto na dimensão reparatória quanto na dimensão do reconhecimento e valorização de sua história, cultura e identidade. "Trata, ele [o Parecer], de política curricular, fundada em dimensões históricas, sociais, antropológicas oriundas da realidade brasileira, com o objetivo explicito de combater o racismo e as discriminações que atingem particularmente os negros" (Diretrizes, 2004, p. 6). Para tanto, de forma propositiva, as diretrizes recomendam a divulgação e produção de conhecimentos; a formação de atitudes, posturas e valores que eduquem cidadãos orgulhosos de seu pertencimento étnico-racial; a criação de condições, no ambiente escolar, para que professores e alunos interajam na construção de uma nação democrática; e sugerem a consolidação/obtenção de direitos que garantam a valorização de sua identidade. No que diz respeito às metas, as diretrizes estabelecem as seguintes:

1) o direito dos negros se reconhecerem na cultura nacional, manifestarem seus pensamentos com autonomia, individual e coletiva, e expressarem visões próprias de mundo;

2) o direito dos negros cursarem cada um dos níveis de ensino das diferentes áreas de conhecimento, com formação para lidar com as tensas relações 
produzidas pelo racismo e discriminações sensíveis e capazes de conduzir à reeducação das relações entre diferentes grupos étnico-raciais.

Em consonância com o debate sobre políticas de reparação, de reconhecimento e valorização da população negra e, também, com o artigo 205 da Constituição Federal de 1988, as diretrizes acentuam o papel do Estado em promover e incentivar políticas de reparações. Quanto à educação das relações étnico-raciais, elas sugerem a necessidade de reeducá-las. Assim, as diretrizes enfatizam que, para reeducar as relações étnico-raciais, impõe-se à educação aprendizagens entre negros e brancos, trocas de conhecimento, quebra de desconfianças, projetos conjuntos para a construção de uma sociedade justa, igual, equânime. Para tanto, impõe-se a necessidade de rever e atualizar o papel da escola, onde a formação para um tipo de cidadania regulada tem se tensionado com a construção/preservação da identidade particular dos afrodescendentes.

Em relação à formação de professores, as diretrizes orientam no sentido de se desfazer a mentalidade racista e discriminadora secular; para a necessidade de superar o etnocentrismo europeu; para a desalienação dos processos pedagógicos; para a construção de projetos pedagógicos, e pedagogias, que desvendem os mecanismos racistas e discriminatórios com o objetivo de reeducar as relações étnico-raciais. Nesse sentido, elas arrolam algumas providências a serem tomadas pelos gestores dos sistemas de ensino e autoridades responsáveis pela política pública educacional:

1) Ampliar o foco dos currículos escolares para a diversidade cultural, racial, social e econômica brasileira;

2) A autonomia dos estabelecimentos de ensino para compor os projetos pedagógicos, no cumprimento ao exigido pelo artigo 26 da Lei n. 9.394/1996, permite que os estabelecimentos se valham da colaboração das comunidades a que a escola serve, do apoio direto ou indireto de estudiosos e do movimento negro;

3) Caberá aos sistemas de ensino, às mantenedoras, à coordenação pedagógica dos estabelecimentos de ensino e aos professores, com base no Parecer, estabelecer conteúdos de ensino, unidades de estudos, projetos e programas, abrangendo os diferentes componentes curriculares;

4) Caberá aos administradores dos sistemas de ensino e das mantenedoras prover as escolas, seus professores e alunos de material bibliográfico e de outros materiais didáticos, relativos à educação das relações étnico-raciais e do ensino de história e cultura afro-brasileira e africana, além de acompanhar os trabalhos desenvolvidos tanto na formação inicial como continuada de professores. 
De acordo com as diretrizes, tais condições são necessárias tanto para a desracialização de uma sociedade que se utiliza da desvalorização da cultura de matriz africana e dos aspectos físicos herdados pelos descendentes de africanos, quanto para o processo de construção da identidade negra no Brasil, de forma condizente com o legado histórico das culturas africanas no país. O Programa "Brasil-África: história cruzadas", ${ }_{13}^{13}$ criado em 2007, pode ser compreendido como uma das estratégias que o governo brasileiro vem desenvolvendo, principalmente nas duas últimas décadas, frente às alterações ocorridas no cenário social e, especificamente, no contexto educacional em relação ao combate a discriminação étnico-racial e, também, pode ser entendido no contexto da atuação da Unesco no Brasil, por meio das contribuições realizadas para o desvendamento do conteúdo sociocultural das relações entre brancos e não brancos.

\section{Negros, afrodescendentes e afro-brasileiros}

No Brasil da década de 1950, a presença da Organização das Nações Unidas (ONU) se deu por intermédio da Unesco. A crença divulgada externamente, por autoridades acadêmicas e políticas, de um país harmônico permitiu que o Brasil fosse selecionado para o desenvolvimento de uma pesquisa sobre aspectos que influenciariam a existência de um ambiente de relações cooperativas entre raças e grupos étnicos.

Os resultados do Projeto Unesco, como foi denominado, inauguraram uma nova fase nos estudos das relações raciais no Brasil que viabilizou a coleta sistemática e intensa de dados, garantindo uma base empírica sólida para o período, permitindo, assim, que as relações entre brancos e negros fossem analisadas, pela primeira vez cientificamente, isto é, com base em métodos quantitativos e qualitativos aceitos pela comunidade acadêmica transnacional e comparadas a de outros países. Um dos maiores legados alcançados com os resultados da pesquisa foram as evidências de que o Brasil não vivia uma "democracia racial", como era divulgado e reconhecido internacionalmente. O país era marcado por conflitos e por grandes desigualdades sociais entre os diferentes grupos étnico-raciais que formavam e formam a sociedade, em especial, entre negros e brancos.

O golpe militar de 1964, que resultou em uma ditadura, restringiu a ampla divulgação dos resultados do Projeto Unesco, situação alterada a partir de meados dos anos de 1970, quando jovens negros participantes de grupos de esquerda passaram a denunciar, em jornais alternativos - a exemplo do Versus, em sua seção Afro-Latino-América -, a discriminação racial e o racismo ${ }^{14}$ no âmbito nacional e transnacional a partir de 1977.

Os processos de luta de libertação que resultaram nas independências daqueles povos que vieram a constituir os novos Estados nacionais africanos, mesmo 
quando consideramos suas variações temporais e dinâmicas coloniais, geraram aspirações de caráter político, como, por exemplo, a formação de um Estado nacional, e também de resgate de histórias locais anteriores ao processo de colonização. Foram aquelas aspirações que explicariam a ampla mobilização dos novos países, por intermédio de algumas de suas lideranças acadêmicas e políticas, para o surgimento de uma História não mais sob ótica dos colonizadores do continente africano.

O resultado foi o desenvolvimento de uma História da África, escrita majoritariamente por africanos, com os seguintes pressupostos científicos: uma abordagem interdisciplinar que contempla o conhecimento antropológico, arqueológico, sociológico, entre outros; uma abordagem continental capaz de integrar as várias regiões internamente ao continente africano e com o mundo; uma abordagem da história com referenciais internos à África; uma abordagem que considerou os africanos de fora, isto é, os da diáspora. Quanto às teses orientadoras, pode-se ressaltar as seguintes: a existência de técnicas políticas e sociais características do continente; a continuidade das civilizações africanas; a abertura do continente para a economia mundial; o duro encontro com outras civilizações e suas consequências - África não começou o processo de escravatura, mas teve a capacidade de negociar (com outras culturas) sua sobrevivência cultural e de resistência (preservar suas matrizes culturais); a ideia de que o renascimento africano se dará com a aproximação com a diáspora africana. ${ }^{15}$

A História Geral da África (HGA), desde a publicação do primeiro dos oito volumes, pela Unesco de Paris, passou a inspirar jovens descendentes de africanos em diferentes regiões do globo e, especialmente, no Brasil. As denúncias sobre discriminação e racismo e a demonstração pública do conteúdo de uma leitura recriada das culturas africanas, por exemplo, por meio dos blocos afros tais como o Olodum e o Ilê Ayê, são aspectos fundamentais do processo da luta política do movimento negro.

A junção entre cultura e política é constitutiva do tipo de ação das denominadas, por seus próprios membros, entidades ou organizações negras. Assim, a reivindicação por educação surge em consonância com o legado das gerações anteriores de militantes da causa negra, mesmo antes do processo de redemocratização do Estado brasileiro. A questão, a saber, é a seguinte: Há algo novo a se dizer sobre as relações raciais no Brasil contemporâneo? A resposta é sim. E a novidade é decorrente da centralidade que a política pública educacional passou a adquirir, para o movimento negro contemporâneo, como lugar de disputa da articulação de dois tipos de demandas que se tenta equacionar em seu interior. A primeira, em relação à qualidade da educação formal que é vista tanto como um direito, quanto como a forma por excelência de mobilidade ocupacional e social. A segunda é que a luta política por mais e melhor educação continua tendo como exigência o resgate da contribuição das culturas africanas para a formação social brasileira, para além das limitações proporcionadas pela agenda de pesquisas das agências de fomento. 
Dessa forma, a obrigatoriedade, em todo o sistema de ensino, de conteúdos que proporcionem o conhecimento de história e cultura afro-brasileira e africana, em toda a educação básica, por um lado, exige mudanças no conteúdo curricular de todos os cursos superiores do país e, por outro lado, é uma oportunidade de uma ressignificação do país e de sua história, levando-se em conta a perspectiva daqueles considerados como o "outro".

Contar a história a partir de sua própria perspectiva foi central na luta política dos africanos junto à Unesco durante e após o processo de luta de libertação. Um dos resultados foi a demonstração de que, contrariamente ao que se argumentava, a África tinha história.

Para a efetivação das transformações ocorridas no contexto socioeducacional brasileiro, considerando a dimensão normativa, a luta política do movimento negro e as exigências práticas em termos da formação dos profissionais de educação para o novo momento, o projeto "Brasil-África: histórias cruzadas", da Unesco, é um marco fundamental.

Quando se considera o papel que o Brasil tem desempenhado como potencial ator global, em especial, na última década, no diálogo sul-sul e com atenção à relação com o continente africano, as expectativas da União Africana em relação à sexta região ${ }^{16}$ e os sentidos da ação do movimento negro brasileiro no que diz respeito à diáspora, é possível pensar a seguinte questão: O que o discurso sobre a diáspora, efetivamente, pode articular?

O discurso sobre a diáspora articula, a partir do simbolismo e de representações que ele emana, expectativas, ações, resultados práticos e dimensões institucionais distintas, a saber:

1) a União Africana se caracteriza como uma confederação de Estados nacionais, na qual têm assento 53 chefes de Estado. De acordo com seu ato constitutivo, foi inspirada nos ideais que nortearam os fundadores da organização continental e gerações de pan-africanistas em sua determinação de promover a unidade, a solidariedade, coesão e cooperação entre os povos da África e os Estados africanos; posteriormente, foram acrescentados no ato constitutivo todos os afrodescendentes dispersos pelo mundo;

2) a partir da influência das culturas africanas que participaram da formação social brasileira e da presença de um grande contingente de população negra, o Estado operacionaliza um discurso pelo qual molda atitudes, representações e políticas. Estas se assentam, sobretudo, na crença da ausência de racismo, na harmonia social brasileira e nas virtudes da brasilidade. A ideia de diáspora africana, portanto, pode ser pensada como 
um dos sustentáculos da política externa brasileira para construção do país como ator global e como o principal elo comercial e econômico com os países africanos, além de possibilitar um discurso intranacional em resposta a setores do movimento negro;

3) o movimento negro não pode mais ser lido como unitário, em termos de sua perspectiva de ação a partir do conceito de diáspora; em particular, na perspectiva de Brah (1996), que propõe a distinção entre o conceito teórico de diáspora e a experiência de diáspora. Com tal distinção, a autora sugere que este conceito seja apreendido como "genealogias" historicamente contingentes, no sentido de Foucault, ou seja, como um conjunto de tecnologias de pesquisa que constroem a história das trajetórias das diferentes diásporas e analisam seus relacionamentos através dos campos sociais, da subjetividade e da identidade. Para a autora, o conceito de diáspora oferece uma crítica aos discursos que fazem exame preconcebido de determinadas origens imutáveis, tendo em conta o desejo de voltar para casa, que não é o mesmo que voltar à "pátria". A distinção é importante porque nem todas as diásporas mantêm uma ideologia de "retorno"; mais ainda, Brah (op. cit.) afirma que o subtexto "lar", que compreende o conceito de diáspora, permite a análise da problemática da posição do sujeito "autóctone" e sua precária relação com os discursos "nativistas".

Em relação aos negros brasileiros, se não encontramos uma ideologia de retorno físico à origem africana, identificamos pelo menos dois discursos distintos: um que dilui a origem africana na brasilidade; outro, no qual a origem africana é discursivamente constitutiva da identidade, daí a utilização recente de expressões como afrodescendente e afro-brasileiro. A impossibilidade de voltar para a casa da mãe África em ambos os discursos permite observar lógicas distintas no uso do conceito de diáspora: uma que contigencia e restringe a origem africana a uma dinâmica nacional; outra na qual aquela origem é utilizada como elemento de crítica da posição do sujeito negro na sua relação com a sociedade que, ao racializar sua pertença étnica, o hierarquiza, podendo ele, no entanto, ao recriar sua origem para além da fronteira nacional numa perspectiva diaspórica, denunciar a forma como a diferença é transformada em desigualdade social. É com base nessa última percepção que é possível repensar o conceito de diáspora contemporaneamente.

\section{Notas}

1. Por meio de Decreto de 8 de setembro de 2000, o então presidente da República Fernando Henrique Cardoso, criou o Comitê Nacional para a Preparação Brasileira na Conferência Mundial contra o 
Racismo, Discriminação Racial, Xenofobia e Intolerância Correlata. O Comitê Nacional foi encarregado de coordenar o processo de discussão dos temas substantivos da Conferência Mundial e sistematizar as contribuições dos órgãos governamentais e de movimentos da sociedade civil interessados na Conferência. Os seminários, com a mesma pauta de discussões, ocorreram em três capitais: Belém, São Paulo e Salvador. Os textos resultantes encontram-se nos Anais com o mesmo nome, publicados pela Secretaria de Estado dos Direitos Humanos do Ministério da Justiça, com o apoio do Instituto de Pesquisas em Relações Internacionais (Ipri) do Ministério das Relações Exteriores, em 2001.

2. O Plano Nacional de Implementação das Diretrizes Curriculares Nacionais para a Educação das Relações Étnico-Raciais e para o Ensino de História e Cultura Afro-Brasileira e Africana é o resultado das solicitações advindas dos anseios regionais, consubstanciadas pelo documento Contribuições para a Implementação da Lei n. 10.639/2003: Proposta de Plano Nacional de Implementação das Diretrizes Curriculares Nacionais da Educação das Relações Étnico-Raciais e para o Ensino de História e Cultura Afro-Brasileira e Africana, fruto de seis encontros denominados Diálogos Regionais sobre a Implementação da Lei n. 10.639/03, do conjunto de ações que o MEC desenvolve, principalmente a partir do surgimento da Secad, em 2004, documentos e textos legais sobre o assunto. Cabe aqui registrar a participação estratégica do Setor de Educação da Unesco do Brasil, do movimento negro, além de intelectuais e ativistas da causa antirracista.

3. A Seppir, criada pelo governo federal no dia 21 de março de 2003, no Dia Internacional pela Eliminação da Discriminação Racial, objetiva o reconhecimento das lutas históricas do movimento negro brasileiro e o estabelecimento de iniciativas contra as desigualdades raciais no país.

4. A Secad, criada oficialmente em julho de 2004, reúne temas como alfabetização e educação de jovens e adultos, educação do campo, educação ambiental, educação escolar indígena e diversidade étnico-racial, temas antes distribuídos em outras secretarias. A criação da Secad marcou a valorização da diversidade da população brasileira, por meio da formulação de políticas públicas e sociais como instrumento de cidadania.

5. Aos Parâmetros Curriculares Nacionais (PCN) acrescentou-se o tema "Pluralidade Cultural", que abarca uma ampla discussão sobre diversidade, ainda insistindo no mito da democracia racial, não especificando a necessidade de um melhor tratamento da questão do negro na sociedade brasileira, reproduzindo um discurso de igualdade e homogeneização da população.

6. O Programa Nacional do Livro Didático (PNLD) promoveu uma avaliação dos livros didáticos, que incluía o quesito racismo e discriminação racial, delineando também novos parâmetros para a inclusão da temática racial nestas obras.

7. Real Academia Espanhola. Consulta feita em 26 fev. 2012.

8. Idem.

9. A denominação "semita" evoca a origem hebraica como descendente de Sem.

10. O uso com esta conotação refere-se ao sétimo significado constante no Dicionário da Real Academia Espanhola.

11. A ideia de "racialização" ou "formação de raça" se baseia no argumento de que a raça é uma construção social e categoria não universal ou essencial da biologia. Raças não existem fora da representação. Em vez disso, elas são formadas na e pela simbolização em um processo de luta pelo poder social e político. O conceito de racialização refere-se aos casos em que as relações sociais entre as pessoas foram estruturadas pela significação de características biológicas humanas, de tal modo a definir e construir coletividades sociais diferenciadas.

12. O conceito de mestiçagem é uma construção que só adquire sentido quando considerada em relação com seu par, a noção de raça. Ele nos conduz a um paradoxo básico da ideia de mestiçagem. Um mestiço se forma a partir de duas ou mais raças. Assim, o paradigma dominante das ciências biológicas afirma veementemente que não existem raças, que só existe uma raça humana. De acordo com esta concepção foi se convencionando a noção de populações humanas como um substituto heurístico do conceito obsoleto de raça, de modo que nos permite continuar usando a ideia de mestiçagem. Contudo, a palavra mestiçagem encontra sua maior difusão no sentido ideológico 
de caracterizar alguns grupos humanos que se autodefinem estrategicamente, frente a outros considerados "puros" ou homogêneos racialmente, como mestiços. Esta ideologia da mestiçagem é especialmente importante na America Latina que se vê mestiça em oposição aos Estados Unidos da América e a África do Sul (durante o regime do Apartheid); nações que se definem como segregadas e, em consequência, não mestiças (Barañano et al., 2007).

13. Desenvolvido por meio da parceria estabelecida entre a Representação da Unesco no Brasil, o Ministério da Educação e a Universidade Federal de São Carlos.

14. A jornalista Neusa Maria Pereira fez parte do núcleo central da editoria Afro-Latino-América, que sacudiu a redação e os leitores a partir da edição 12 de Versus, reabrindo um espaço alternativo para a imprensa negra independente no Brasil. Neusa Maria Pereira estreou em Versus n. 11 , nas páginas centrais, quando redigiu um contundente manifesto em defesa da dignidade das mulheres negras em uma sociedade racista. O grupo Afro-Latino-América acabou por ocupar um largo espaço político e cultural no país, estando na origem das articulações do Movimento Negro Unificado. As principais lideranças do núcleo foram Hamilton Bernardes Cardoso, Wanderlei José Maria, os irmãos Prudente, José Adão de Oliveira, Maria Dulce Pinheiro, Jamu Minka e outros tantos, todos por inspiração inicial e iniciativa do poeta Oswaldo Camargo (síntese retirada de www.versus.jor.br/livro_completo_versus.php).

15. A síntese foi realizada a partir das informações passadas por Elikia M’Bokolo no lançamento da versão em língua portuguesa dos oito volumes da História Geral da África (Unesco), na Universidade Federal do Recôncavo Baiano, no dia 2 de abril de 2011.

16. O Protocolo de Emendas ao Ato Constitutivo da União Africana, adotado pela Sessão Extraordinária da Primeira Assembleia dos Chefes de Estado e de Governo em Addis Abeba, Etiópia, em Janeiro de 2003, e em particular o artigo $3^{\circ}$ (q), que convida a diáspora africana a participar como um importante componente na construção da União Africana. O Protocolo insiste na ideia de que os descendentes de africanos, em especial os residentes no continente americano, formariam a sexta região do continente.

\section{Referências}

ANDERSON, B. Comunidades imaginadas: reflexões sobre a origem e difusão dos nacionalismos. São Paulo: Cia das Letras, 2008.

BARAÑANO, J.L.G. et al. Diccionario de relaciones interculturales: diversidad y globalización. Madrid: Complutense, 2007.

BARKER, C. Cultural studies: theory and practice. 4. ed. London: Sage, 2012.

BHABHA, H. Narrar la nación. In: BHABHA, H (Comp.). Nación y narración: entre la illusion de una identidad y las diferencias culturales. Madrid: Siglo XXI, 2010. p. 444.

BILDEN, R. Brazil, laboratory of civilization. New York: The Nation, 1929.

BRAH, A. Cartographies of Diaspora: contesting identities. London: Routledge, 1996.

BRENNAN, T. La nostalgia nacional de la forma. In: BHABHA, H (Comp.). Nación y narración: entre la illusion de una identidad y las diferencias culturales. Madrid: Siglo XXI, 2010. p. 65-97.

GELLNER, E. Nations and nationalism. Oxford: Blackwell, 1983. 
GOMES, N.L. A contribuição dos negros para o pensamento educacional brasileiro. In: SILVA, P.B.G.; BARBOSA, L.M.A. (Org.). O pensamento negro em educação no Brasil: expressões do movimento negro. São Carlos: Edufscar, 1997. p. 17-30.

GOMES, N.L. Trajetórias escolares, corpo negro e cabelo crespo: reprodução de estereótipos e/ou ressignificação cultural? In: REUNIÃO ANUAL DA ANPEd, 25., 2002, Caxambú. Anais... Caxambú, 2002.

GOMES, N.L. Alguns termos e conceitos presentes no debate sobre relações raciais no Brasil: uma breve discussão. In: BRASIL. Ministério da Educação. Secretaria de Educação Continuada, Alfabetização e Diversidade. Educação antirracista: caminhos abertos pela Lei Federal n. 10.639/03. Brasília, DF: MEC/Secadi, 2005. p. 39-61.

GOMES, N.L. Diversidade cultural, currículo e questão racial: desafios para a prática pedagógica. In: ABRAMOWICZ, A.; BARBOSA, L.M.A.; SILVÉRIO, V.R. (Org.). Educação como prática da diferença. Campinas: Armazém do Ipê; Autores Associados, 2006. p. 184.

GONÇALVES, L.A.O.; SILVA, P.B.G. Multiculturalismo e educação: do protesto de rua a propostas e políticas. Educação \& Pesquisa, São Paulo, v. 29, n. 1, jan./jun. 2003.

GUIMARÃES, A.S. Intelectuais negros e modernidade no Brasil. In: ENCONTRO ANUAL DA ANPOCS, 26., 2002, Caxambú. Anais... Caxambú: Anpocs, 2002. (mimeo.).

HALL, S. A centralidade da cultura: notas sobre as revoluções culturais do nosso tempo. Educação \& Realidade, Porto Alegre, v. 22, n. 2, p. 15-46, jul./dez. 1997.

HALL, S. Quem precisa de identidade? In: SILVA, T.T.; WOODWARD, K. (Org.). Identidade e diferença: a perspectiva dos estudos culturais. Rio de Janeiro: Vozes, 2004. p. 103-133.

HALL, S. A identidade cultural na pós-modernidade. Trad. Tomaz Tadeu da Silva e Guacira Lopes Louro. Rio de Janeiro: DP\&A, 2005.

HALL, S. Stuart Hall por Stuart Hall: uma entrevista com Stuart Hall. In: CHEN, K.-H. Da diáspora: identidade e mediações culturais. Belo Horizonte: UFMG, 2006.

HOBSBAWN, E.; RANGER, T. The invention of tradition. Cambridge: Cambridge University, 1983.

HUGHES, E. Race relations and sociological imagination. American Sociological Review, New York, v. 28, n. 6, p. 879-890, Dec. 1963.

MISKOLCI, R. O desejo da nação. 2012. (mimeo.).

RENAN, E. Qué es una nación? In: BHABHA, H. (Comp.). Nácion y narración: entre la illusion de una identidad y las diferencias culturales. Madrid: 2010. p. 21-38. 
RODRIGUES, T.C. Movimento negro no cenário brasileiro: embate e contribuições à política educacional nas décadas de 1980-1990. 2005. Dissertação (Mestrado em Sociologia) - Universidade Federal de São Carlos, São Carlos.

RODRIGUES, T.C. A ascensão da diversidade nas políticas educacionais contemporâneas. 2011. Tese (Doutorado em Educação) - Universidade Federal de São Carlos, São Carlos.

SANTOS, E.L. Racismo e injúria: erosão e persistências no ideário da democracia racial. 2010. Dissertação (Mestrado em Sociologia) - Programa de Pós-Graduação em Sociologia, Universidade Federal de São Carlos, São Carlos.

SEGURA-RAMÍREZ, H.F. Tiro no pé: biopolítica, relações racializadas, academia e poder no Brasil 1823-1955/1997-2006; epistemologia do conhecimento (em rap menor). 2006. Tese (Doutorado em Sociologia) - Instituto de Filosofia e Ciências Humanas, Universidade Estadual de Campinas, Campinas.

SILVAJUNIOR., H. Educação, diversidade e igualdade racial: marcos legais e conceituais. 2012 (mimeo.).

SILVÉRIO, V.R. Ação afirmativa e o combate ao racismo institucional no Brasil. Cadernos Pesquisa, São Paulo, n. 117, p. 219-246, nov. 2002.

SILVÉRIO, V.R. Ação afirmativa no Brasil: trajetória de um dissenso. In: ENCONTRO ANUAL DA ANPOCS, 27., 2003, Caxambú. Anais... Caxambú: Anpocs, 2003.

SILVÉRIO, V.R. A (re)configuração do nacional e a questão da diversidade. In: ABRAMOWICZ, A.; SILVÉRIO, V.R. (Org.). Afirmando diferenças: montando o quebra-cabeça da diversidade na escola. Campinas: Papirus, 2005. p.108.

SILVÉRIO, V.R. A sociologia, a escola e as diferenças étnico-raciais. In: ENCONTRO ANUAL DA ANPOCS, 32., 2008, Caxambú. Anais... Caxambú: Anpocs, 2008.

SILVÉRIO, V.R.; MOYA, T.S. (Org). Educação, diferença e desenvolvimento nacional. São Carlos: Edufscar, 2009.

SLENES, R. A importância da África para as ciências humanas. História Social, Campinas, v. 19, p. 19-32, 2010.

\section{Documentos oficiais}

BRASIL. Constituição (1988). Constituição da República Federativa do Brasil. Brasília, DF: Senado Federal, 1988.

BRASIL. Ministério da Educação. Parecer CNE/CP n. 3, de 10 de março de 2004. Institui as diretrizes curriculares nacionais para a educação das relações étnico-raciais e 
para o ensino da história e cultura afro-brasileira e africana. Brasília, DF, 2004.

BRASIL. Ministério da Educação. Secretaria de Políticas de Promoção da Igualdade Racial (Seppir). Plano Nacional de Implementação das Diretrizes Curriculares Nacionais para a Educação das Relações Étnico-Raciais e para o Ensino de História e Cultura AfroBrasileira e Africana. Brasília, DF: MEC/Seppir, 2006.

CONSTITUTIVE ACT OF THE AFRICAN UNION. 2003.

\section{Sites}

UNESCO. Coleção História Geral da África. Brasília, DF: Unesco; MEC/Secad; Ufscar, 2010. 8v. Disponível em: <http://www.unesco.org/new/en/brasilia/special-themes/ ethnic-and-racial-relations-in-brazil/general-history-of-africa/>

UNESCO. Programa Brasil-Africa: histórias cruzadas. Brasília, DF, 2007. Disponível em: $<\mathrm{http}$ ://www.unesco.org/new/en/brasilia/special-themes/ethnic-and-racial-relationsin-brazil/brazil-africa-project/\#c155014>

Recebido em 8 de agosto de 2012.

Aprovado em 24 de agosto de 2012. 